\title{
The English Monolingual Dictionary: Its Use among Second Year Students of University Technology of Malaysia, International Campus, Kuala Lumpur
}

\author{
Amerrudin Abd. Manan and Khairi Obaid Al-Zubaidi \\ (University Technology Malaysia, Kuala Lumpur, Malaysia) \\ doi:10.7575/aiac.alls.v.2n.2p.140
}

\begin{abstract}
This research was conducted to seek information on English Monolingual Dictionary (EMD) use among $2^{\text {nd }}$ year students of Universiti Teknologi Malaysia, International Campus, Kuala Lumpur (UTMKL). Specifically, the researchers wish to discover, firstly, the students' habit and attitude in EMD use; secondly, to discover their knowledge with regard to the language learning resources available in EMD; thirdly, to discover their skill in using EMD, and finally, to discover whether there were formal instructions in EMD use when they were studying in their former schools and tertiary education. One hundred and ninety-six students took part in the survey by answering a questionnaire. The results of the study reveal that the respondents were poor users of EMD. They rarely consulted the EMD; their knowledge of the language learning resources in the EMD was limited; most perceived their EMD skill as average, and there was no instruction in EMD when they were at tertiary education and previously when they were at school.
\end{abstract}

\section{Introduction}

The English monolingual dictionary (EMD) is an important tool for learning the English language. From the EMD, students can learn many aspects of the English language, for example, meaning of words and phrases, pronunciation, word stress, spelling, words' part of speech, word collocation, the use of target words in context, etc. As in the words of Berwick and Horsfall (1996), when used appropriately, the EMD can be a valuable learning resource for the ESL/EFL learners.

The EMD is thus particularly important for students of ESL or EFL, for being in a non-native environment, ignorance and uncertainties about the correct meaning of words, correct lexical phrases, pronunciation, stress, and how target words are actually used in context are common. 
As students cannot always ask their teachers on those language items they wish to learn, and as there is constantly the absence of a correct model to follow, the EMD can help. The EMD can help students to obtain some degree of independence in their learning of the English language.

The EMD, arguably, is also a tool to help students to encourage them to think less in their mother tongue. When students search for meaning of words from a bilingual dictionary, it may encourage them to think in their L1. Thinking in L1 while learning L2 may minimize and slow down the learning of L2. Schofield (2002, cited in Petrylaite, Vaskeliene \& Vezyte, 2008), argues that learners need to get into the habit of thinking in the target language, and that they would not be efficient comprehenders and users of the target language if they always resort to translation when using the bilingual dictionary. The statement by Petrylaite et al. (2008, p. 78) underscores the importance of the monolingual dictionary in aiding students to think more in L2:

...monolingual dictionaries present their L2 information in L2. With their definitions and examples, they make every dictionary search a useful experience in more ways than the one perhaps originally intended; ... In addition, the user learns to think in L2 instead of relating every new word s/he comes across to his or her own mother tongue (L1).

Though few would argue against the importance of the EMD in helping students to have some degree of learning independence for English, we still do not know much about how it is being perceived and used by students. We are still ignorant about students' knowledge of the EMD as a language learning tool, their skills in using EMD, and their attitude towards EMD in language learning. According to Winkler (2001) and Hartman and James (1998), we still do not know much about the behaviour and preferences of dictionary users and the complex operations involved in dictionary consultations. Brumfit (1985) argues that dictionary use is quite often taken for granted and under-utilized. According to Tickoo (1989), the dictionary is a rich learning resource, but it has been poorly used. Insufficient assistance given to students to optimize the use of dictionaries, he says, is the reason why students fail to exploit the immense information available in the dictionary. We are of the opinion that the majority of ESL/EFL students may still see the dictionary as a tool solely to learn meaning of words.

This research came about after the researchers noticed the stark contrast in dictionary use between the local University Technology Malaysia, Kuala Lumpur (UTMKL) students, and 
foreign students. Both groups of students studied at the university. From the researchers' observation after teaching the foreign students for 3 semesters, they discovered that foreign students from China, Iran and Iraq were frequent and avid users of the pocket electronic dictionary. The local students, however, were clearly not dependent on the dictionary. Due to the stark difference in dictionary use between the 2 groups of students, this study was initiated to investigate the local students EMD use. This research is therefore conducted to investigate the following:

1) To discover the second year UTMKL students' habit and attitude with regard to dictionary use, especially EMD use,

2) To discover their knowledge about the language learning resources available in EMD,

3) To discover their skill in using the EMD,

4) To discover whether there was formal instructions received by them in EMD use at their school/tertiary education.

\section{Literature review}

Sanchez (2005) reported that her research subjects used bilingual English-Spanish dictionary to look for equivalent terms, spelling and examples. Her subjects also referred to the monolingual dictionary to look up definitions of words and spelling. Concerning difficulties in dictionary use, Sanchez reported that the problems her subjects mentioned when looking up words in the dictionary include not finding words they looked for, difficulty to find the specific information they were looking for and inability to understand meaning of words. According to Sanchez, her subjects attributed the reasons for the difficulties to their lack of familiarity with the dictionary, lack of dictionary skills and unclear layout of the dictionary. They also indicated that the majority of them had not been taught how to use dictionaries.

Battenburg (1989) listed the possible information his research subjects would look up for when consulting the EMD. These include spelling, pronunciation, parts of speech and syntactic patterns, definitions, etymology, illustrations, derived forms, synonyms, cross references, usage labels and pictures and diagrams. From his study of the subjects above, it was found that the majority of the elementary, intermediate and advanced students did check spelling from the EMD. Concerning pronunciation, many of the elementary and intermediate students did look up for pronunciation from the EMD, but few advanced students did so. With 
respect to parts of speech and syntactic patterns, it was noticed that the advanced students showed a marked disinclination to look up for these in the EMD compared to the elementary and the intermediate students. Where definitions of words are concerned, it was observed that although all 3 groups showed their keenness for this, again the advanced group showed their lesser interest in this area. All three groups of students were reported to have shown a similar disinterest in looking for information of words' etymology. So was the interest in usage labels, where all 3 groups were seen to have least referred to this. As for derived forms, many elementary students showed their keenness in this, as opposed to the intermediate and the advanced groups who showed their disinterest in this area. With regard to cross-references, pictures and diagrams, they were mostly referred to by the elementary group compared to the other two groups. Battenberg also reported that when the 3 groups of students were asked if they were ever taught how to use a dictionary in English class, half of the students from the elementary and advanced group said that they had not received such instruction. The majority of the intermediate learners said that they had received such instruction only because one ESL instructor had included the instruction in the curriculum for one of the academic terms.

Nesi and Haill (2002) looked at the problems which students faced when looking up words in the dictionary. Their subjects were asked to report on the way they had consulted their dictionaries based on 89 assignments given to them over a period of 3 years. The results of their study revealed that while the majority of the words were looked up successfully, more than half of the subjects were unsuccessful in at least one of five dictionary consultations. Of particular difficulty to the subjects were in selecting appropriate entries and sub-entries in their dictionaries. There were also some serious errors in entry interpretation which their subjects were not aware of.

Diab and Hamdan (1999) report the findings of a case study which investigated how 50 Jordanian Arab university students of English interacted with words and dictionaries while reading a specialized text in linguistics. The results of their study show that meaning and pronunciation were the prime purposes of dictionary use. It was also found that the overwhelming majority of the dictionary look-ups were not preceded by any pre-dictionary use strategy, suggesting that there was no instruction in dictionary use for the students. The study also showed that EMD were used more frequently than bilingual ones, and that they were also found to be more useful than the latter. 
In response to students' recurrent queries to teachers as to which dictionary is best for them, Koren (1997) compares the advantages and disadvantages of several types of modern dictionaries both from the teachers and researchers as well as from the students' points of view. To show her students which dictionary is useful to them, Koren put up a comparison and contrast table to her students so that they could judge by themselves the usefulness of each dictionary. On the table's extreme left is the properties column. Under this column, word entry properties like phonetic information, etymology, grammatical information, meaning information, spelling, etc. are listed. The four other columns following the previous column and progressing to the right are the names of the 4 dictionary types, i.e. EE (English-English), EH (English-Hebrew), EEH (English-English-Hebrew) and E (Electronic). Where there is a plus sign under each dictionary type on the row corresponding to each property, for example, for the item, picture, this means that the dictionary has pictures, and the minus sign denotes an absence of this property. From the table, the students could see that the EE (the monolingual dictionary) has most of the advantages, while the electronic dictionary has the fewest. However, Koren noted that her students preferred the bilingual to the monolingual dictionary, even though the latter has properties like antonyms, pictures and phonetic information. This preference, she said is due to their preference for translation and also their indifference to the advantages which the monolingual dictionary could offer.

Winkler (2001) carried out a study to investigate the problems EFL learners encountered when using an Oxford Advanced Learner's Dictionary, Fifth Edition, in book form and on CD-ROM. In the course of completing a writing task by her student participants, they had to seek assistance from the dictionaries above. The problems the students encountered revealed a lack of dictionary-using skills in certain areas. Some of the participants were not aware of the information that can generally be found in an English learner's dictionary. They were ignorant of not only the preliminary front pages and the appendices but also the structure of individual entries. Also even higher-level students had difficulty with scanning long entries or finding particular details and often gave up such searches. Abbreviations, codes and symbols were avoided altogether and the grammatical and syntactical information needed were derived from example sentences.

Taylor (2004) comments that although the EMD is an essential and invaluable resource for ESL students at various levels, many of the dictionaries recommended to students were too sophisticated for students' vocabulary abilities. She is also critical of many ESL instructors 
who seem to assume that all ESL students are equipped with the knowledge of how an EMD functions and is used. In her opinion, a good EMD should contain a list of possible definitions of a word presented in order of frequency of use (most common to least common); definitions that show high levels of differentiation to enable students to become familiar with the various uses of a word in which some are polysemous; definitions which are followed by useful and clear contextual examples, and finally entries that present multiple pieces of information in a clear, organized and non-intimidating manner for the user.

Petrylaite et al. (2008) investigated 88 ESP students' use of the different types of dictionaries, the problems they encountered during dictionary consultations and the opinions they had about their own dictionary skills. Their study revealed that an overwhelming majority owned a bilingual dictionary while only a few owned an EMD. When asked about their frequency of dictionary use, more than half said that they consulted the dictionary 3 or 4 times per week, and few consulted it every day. For the questions on reasons for looking up words, an overwhelming majority consulted the dictionary for meaning followed by spelling, grammar, usage, phrasal verbs, derivatives, compounds, pronunciation, idioms, synonyms/definitions and finally, collocations, respectively. Concerning the problems they encountered when looking up words in EMD, many were given, some of which are: word is not there, information needed is not given, entries are too long, example sentences are not helpful and word combination is not given. The majority, however, gave definitions which are not clear as the most notorious problem. When asked for the reasons which they thought caused the above difficulties, the subject responses were: lack of familiarity with the dictionary, lack of dictionary skills, unclear layout of the dictionary, difference between British and American English and too little information given in dictionary.

Besides investigating the effects of the use and non-use of dictionaries on their subjects' performance on EFL reading tests, Bensoussan, Sim and Weiss (1984) also investigated students' dictionary use and preferences and their teachers' opinions of the students' dictionary use and preferences. Among others, their research reveals that less proficient students did show a greater need to use dictionaries than the better students. Whereas the better students indicated preference for EMD, the less proficient indicated their preference for bilingual dictionaries. With regard to the teachers' opinion on whether the students were effective dictionary users, they were generally critical of this, believing that the students were not, although the students thought they were effective users. Their research also reveals that 
less proficient students lack the language skills to benefit from the EMD, whereas more proficient students know enough to do without the dictionary. The implications to the teacher, they conclude, are that they have to increase students' awareness of word families, parts of speech and sentence structure when working with the dictionary. They can also help students distinguish which words are likely to be important, so that students can focus their attention on those and avoid looking up every unknown word.

\section{Methodology}

For this research, the researchers obtained the participation of second year UTMKL students who took the UDB 2332 English for Professional Communication course. The students were engineering students who took the diploma programme which lasted 3 years, and they were about 19 years old. Cumulatively, they had learned English as a second language at school and at UTMKL for at least 12 years. Based on their experience in teaching the students, the researchers would roughly put the majority of them as low intermediate in terms of their level of English at the GCE O' level. Out of all 253 students who received the questionnaire (in appendix 1, adapted from Winkler, 2001), the researchers got back 169 (67\%). Nine of the

questions in the questionnaire were objective questions, and only one was subjective (see appendix 1). The questionnaire was designed to obtain data on the following domains:

1) To discover the second year UTMKL students' habit and attitude with regard to dictionary use, especially EMD use,

2) To discover their knowledge about the language learning resources available in EMD,

3) To discover their skill in using the EMD,

4) To discover whether there was formal instructions received by them in EMD use at their school/tertiary education.

\section{Results}

Table 1 illustrates the language medium of dictionaries which the respondents prefer:

Table 1: Language medium of dictionary preferred

\begin{tabular}{lc}
\hline Language Medium & Percentage \\
\hline Bilingual (English-Malay/Chinese/Tamil and vice versa) & 60 \\
Both & 28 \\
EMD (English-English) & 12 \\
\hline
\end{tabular}


More than half of the respondents surveyed prefer consulting the bilingual dictionary, while only a small percentage (12\%) prefer consulting the EMD.

Table 2: Frequency of look-up from EMD

\begin{tabular}{lr}
\hline Frequency & Percentage \\
\hline Rarely & 46 \\
$3-5$ times per week & 22 \\
Once a week & 20 \\
Never & 10 \\
Every day & 2 \\
\hline
\end{tabular}

Table 2 illustrates the frequency of look-up from the EMD. The majority said they rarely looked up words from the EMD, while only 10\% said that they never consulted it.

Table 3: Reasons for not looking up words in EMD

\begin{tabular}{lr}
\hline Reasons & Percentage \\
\hline Hard to understand definition in dictionary & 45 \\
Other information about words in dictionary are too technical to & 27 \\
understand & 23 \\
It takes too long to find meanings of words from the EMD & 5 \\
Others & \\
\hline
\end{tabular}

Table 3 illustrates the reasons why the respondents did not have the habit of looking up words from the EMD. Nearly half of the respondents said that they did not understand the definition of words given in the EMD. A few (27\%) said that they found some information about words in the EMD too technical to understand, while $23 \%$ said that it took too long to find the meanings of words in the EMD.

Table 4: Respondents' perception of their skill in using the EMD

\begin{tabular}{lr}
\hline Skill level & Percentag \\
\hline Average & 71 \\
High & 13 \\
Low & 10 \\
Very high & 4 \\
Very low & 2 \\
\hline
\end{tabular}

Table 4 illustrates the respondents' perception of their skill in using the EMD. The majority viewed their skill as average. 
Table 5: Respondents' experience in attending classes in which EMD skills are taught

\begin{tabular}{lr}
\hline Attendance & Percentage \\
\hline No & 94 \\
Yes & 6 \\
\hline
\end{tabular}

Table 5 shows the percentage of respondents who had attended classes in which explicit EMD skills were taught. An overwhelming majority (94\%) had not had any such class before.

Table 6: Respondents' perception on the importance of EMD in language learning

\begin{tabular}{lr}
\hline The importance of EMD & Percentag \\
\hline Important & 85 \\
Not sure & 13 \\
Not important & 2 \\
\hline
\end{tabular}

Table 6 shows the respondents' perception of the importance of EMD in language learning. The majority agreed that it was important.

Table 7: Respondents' keenness to attend an EMD class if it is held at the university

\begin{tabular}{lr}
\hline Keenness & Percentage \\
\hline Yes & 47 \\
Not sure & 46 \\
No & 7 \\
\hline
\end{tabular}

Table 7 shows the respondents' keenness in attending a special EMD class if it was held at the university. The data shows that only about half of the respondents indicated their keenness, while the other half were not sure. A small percentage indicated that they were not keen.

Table 8: Increased frequency of use for highly skilled respondents at using the EMD

\begin{tabular}{lr}
\hline Increased frequency & Percentage \\
\hline Yes & 68 \\
Not sure & 29 \\
No & 3 \\
\hline
\end{tabular}

The majority indicated that they would use the EMD more frequently if they were good at using it. 
Table 9: The reason/s for referring to the EMD

\begin{tabular}{lr}
\hline Reasons & Percentage \\
\hline Learn meanings of new words & 79 \\
To expand my vocabulary & 34 \\
To see how words are used in the example sentences & 20 \\
To check spelling & 17 \\
To improve my English & 16 \\
To speak better & 9 \\
To improve my writing & 7 \\
To learn grammar & 7 \\
To learn pronunciation & 7 \\
To learn synonym & 6 \\
\hline
\end{tabular}

Table 9 illustrates the reasons why they consulted the EMD. It can be seen that vocabulary learning seems to be the main concern of the respondents for consulting the EMD (for example, learning meanings of words, to expand one's vocabulary and to learn synonym).

Table 10: The type of dictionary used by respondents

\begin{tabular}{lr}
\hline Dictionary type & Percentage \\
\hline Desk dictionary & 47 \\
Small pocket booklet dictionary & 31 \\
Pocket electronic dictionary & 9 \\
Online dictionary & 8 \\
Other & 5 \\
\hline
\end{tabular}

Finally, table 10 illustrates the dictionary types used by the respondents. It was found that the desk dictionary (half size A4 paper) was the most popular among the respondents.

\section{Discussion}

Only a small minority of the students preferred using the EMD. This suggests that the majority of them were not comfortable with the EMD. In terms of frequency of use, most students were infrequent and some were non-users of the EMD, indicating their poor habit in this regard. Data reveals that this is because of several reasons: they found it hard to understand the definition of words in the EMD; they found some of the information about words in the EMD too technical to understand, and it took them too long to find the meanings 
of words in the EMD. The majority perceived their skill in EMD use as average. These three reasons were cited because formal instruction in EMD was almost non-existent.

An overwhelming majority of the students had not had any experience of attending classes where explicit dictionary skills were taught. This figure suggests that EMD skills were not taught to the students at the primary, secondary and at the tertiary level education in the country. Nevertheless, at the back of the respondents' mind, they were aware of the importance of the EMD in learning English, hence indicating their positive attitude towards it.

However, it is interesting to note that although they were mostly aware of its importance in language learning, about half of them indicated their uncertainty about attending a special class for EMD skills if it was held at the university. A possible explanation for this could be due to their worry about having to attend extra classes besides the regular classes which they already had then. It may mean an added burden for the students, hence their uncertainty.

In terms of frequency of use assuming they were skilled users of EMD, the majority indicated their willingness to use it more frequently. This again suggests their positive attitude towards EMD use. The Education ministry and Malaysian universities should thus take advantage of this by introducing EMD skills in the classroom so that some degree of independence in language learning and the great potential of the EMD as a language learning tool could be fully exploited.

From the answers given by the students when asked to list down the reasons why they consulted the EMD, it can be deduced that although they had a positive attitude towards it, their knowledge of the EMD as a language learning resource was very limited. They consulted the EMD mainly because they wished to learn the meaning of new vocabulary. Although there are other equally important reasons for consulting the EMD apart from the concerns of vocabulary, they were very rarely or never mentioned, suggesting the students' limited knowledge of EMD as a language learning tool. Aspects like pronunciation, stress, grammar, spelling, collocation, word derivatives, lexical phrases, idiomatic expression, taboo words, slang terms, etc. were generally unfamiliar to them.

Where dictionary type is concerned, it was found that the desk dictionary (half size A4 paper) was the most popular among the students. The students were thus quite traditional in terms of 
dictionary technology. Compared to the foreign students who seemed to be habitual users of the pocket electronic dictionary, this type of dictionary was not popular among the second year UTMKL local students although it is available in the market. Only very few of them said that they used pocket electronic dictionary. The price of the electronic dictionary may also be the discouraging factor.

\section{Conclusion}

This research seems to explain the problem noticed by the researchers. The second year local students were clearly not dependent on the EMD not because they were very good at English, but rather they were unskilled in its use. Because EMD skills were not taught and practiced, they found the EMD too hard and too technical.

On the point that they found it hard to understand the definition in the dictionary, the argument is that students should be explicitly shown that EMD tend to use the common core vocabulary. For example, Hornby's (2000) desk EMD uses the 3000 defining vocabulary definitions which are not too difficult because they are highly frequent, common words. They were carefully chosen according to their frequency in the language and their value to students as the 'core vocabulary' of English. If this was demonstrated to students, i.e. that the explanations are not as difficult as they think, they may be less lukewarm towards the EMD.

On the point that they were bothered that looking up words in the dictionary was too timeconsuming, the argument is that this is possibly because of lack of practice in word searching. Constant practice develops skill, and word search may not be time-consuming anymore. The foreign students do not seem to be bothered by this, suggesting that they were more tolerant than the second year local students in using the dictionary due to constant practice.

With respect to the second year students' preference for the bilingual dictionary, although some language teachers believe that bilingual dictionary is also a helpful vocabulary learning tool, there are language experts who think otherwise, i.e. the bilingual dictionary can encourage students to habitually resort to translation when learning the second language. Translation, arguably, may slow down the process of learning the L2. Using the bilingual dictionary may also encourage students to think that there is always a one-to-one correspondence between words in the L2 and L1, and that it encourages direct translation. The researchers therefore believe that the use of bilingual dictionary should be minimized. 
The importance of EMD skills may have been overlooked by the Education Ministry, and it may think that students would pick up the skills by themselves. But this research has suggested otherwise. EMD skills are not something which comes naturally and that even after reaching the university level (which means that students had learned English as a second language for 12 years), many still regard their EMD skill as average. This research has also shown that because of the absence of explicit EMD teaching, the respondents' knowledge of the EMD as a language learning tool was also inferior, and this may in turn result in poor vocabulary knowledge among the students.

One of the macro language skills that could be adversely affected by poor vocabulary knowledge is reading comprehension. Research has shown that poor vocabulary knowledge may result in poor reading comprehension skill (Beck \& McKeown, 1991; Haynes \& Baker, 1993; Koda, 1989; Qian, 1999; Ulijin \& Strother, 1990). Poor reading comprehension skill may thus put students in the vicious circle, where poor reading comprehension results in poor vocabulary gains. English language teachers could address this problem by explicitly teaching EMD skills.

In terms of dictionary type, the researchers are of the opinion that pocket electronic dictionary may promote frequency in use as it is more convenient than the desk dictionary due to its portability. The desk dictionary, in contrast, may limit frequency of use due to its bulk. Students may not be carrying the desk dictionary around and they may not use it while waiting in a queue, or while boarding a bus when going back to their hometowns. The researchers therefore recommend that they use pocket electronic dictionary so that they, like the foreign students, can increase their frequency in EMD use anywhere and at anytime.

Although the EMD is a great learning tool for vocabulary and language learning, it has not been tapped by schools and universities in the country. Dictionary learning in Malaysian schools has apparently been taken for granted. Hopefully this research may open the eyes of educationists in Malaysia so that EMD skill is seen as a necessity. A conclusion that can be drawn from this research is that there is likelihood that EMD teaching may be well received by university students at UTMKL and perhaps elsewhere too in the country judging from their positive attitude towards it. 
EMD publishers, for their part, should also think about making the EMD more user-friendly, less technical, easy and more attractive to students. The Education ministry who is always very concerned with the command of Malaysian students with respect to the standard of English should start promoting the monolingual electronic English dictionary among students at the tertiary level to increase their frequency of use. Some mobile telephone companies which have started incorporating electronic English dictionary features in their mobile phones should perhaps expand this feature so that students, who generally seem to adore gadgets, could use them anytime and anywhere.

\section{Reference}

Battenburg, J. (1989). A Study of English Monolingual Dictionaries and their Users. Unpublished Doctoral Dissertation, Purdue University.

Beck, I.L. and McKeown, M.G. (1991) "Conditions of Vocabulary Acquisition." In Barr, R.; Kamil, M.L.; Mosenthal, P. and Pearson, P.D. (eds.) The Handbook of Reading Research II, 789-814.

Bensoussan, M.; Sim, D. \& Weiss, R. (1984) "The Effect of Dictionary Usage on EFL Test Performance Compared with Student and Teacher Attitudes and Expectations." Reading in a Foreign Language. Vol. 2 (2), 262-276.

Berwick, G. \& Horsfall, P. (1996) Making Effective Use of the Dictionary. London: Centre for Information on Language Teaching and Research.

Brumfit, C.J. (1985) in Preface to R. Ilson (Ed.), Dictionaries, Lexicography and Language Learning. Oxford: Pergamon Press in Association with the British Council.

Diab, T.A. \& Hamdan, J.M (1999) "Interacting with Words and Dictionaries: the Case of Jordanian EFL Learners." International Journal of Lexicography. Vol. 12 (4), 281-305.

Hartman, R.R.K. \& James, G. (1998) Dictionary of Lexicography. London, New York: Routledge.

Haynes, M. and Baker, I. (1993) "American and Chinese Readers Learning from Lexical Familiarisation in English text.” In Huckin, T. (ed.) Second Language Reading and Vocabulary Learning. Norwood, NJ: Ablex, $153-180$.

Hornby, A.S. (2000) Oxford Advanced Learner's Dictionary of Current English. Oxford: Oxford University Press.

Koda, K. (1989) "The Effects of Transferred Vocabulary Knowledge on the Development of L2 Reading Proficiency." Foreign Language Annals, 22, 529.

Koren, S. (1997) "Quality versus Convenience: Comparison of Modern Dictionaries from the Researcher's, Teacher's and Learner's Points of View." TESL-EJ. Vol.2 (3), 1-12.

Nesi, H. \& Haill, R. (2002) "A Study of Dictionary Use by International Students at a British University." International Journal of Lexicography. Vol. 15 (4), 277-305.

Petrylaite, R.; Vezyte, T. \& Vaskeliene, D. (2008) "Changing Skills of Dictionary Use." Studies About Language. No. 12, 77-82, on www.ceeeol.com

Qian, D.D. (1999) "Assessing the Roles of Depth and Breadth of Vocabulary Knowledge in Reading Comprehension." Canadian Modern Language Review, 56, 282-307, Unpublished Doctoral Dissertation, University of Toronto.

Sanchez, M. M. (2005) "Research on Dictionary Use." Translation Journal. 1-10.

Taylor, L. (2004) "Considerations of Choosing an English-English Dictionary for ESL Students." The Internet TESL Journal. Vol. X (7), 1-4, on http://iteslj.org. Consulted on 30 January, 2009.

Tickoo, M.L. (Ed.) (1989) Learners' Dictionaries: State of the Art. Singapore: SEAMEO Regional Language Centre.

Ulijin, J.M. and Strother, J.B. (1990) "The Effects of Syntactic Simplification on Reading EST texts as L1 and L2." Journal of Research in Reading, 13, 38-54.

Winkler, B. (2001) "Students Working with an English Learner's Dictionary on CD-ROM." [Consulted on 30th January 2009, from http://elc.polyu.edu.hk/Conference/papers2001/winkler.htm] 


\section{Appendix 1}

This questionnaire is about dictionary use in learning English language. It seeks to find information on your general knowledge about the dictionary, your skills in using the dictionary, your attitude towards the dictionary, and your habit with respect to dictionary use. Please respond by circling the best options and/or by writing down your answers in the blanks. Please be honest when answering the questions and answer all questions.

1. In terms of language, what kind of dictionary do you usually refer to?

A. bilingual (Malay, Chinese, Tamil-English or vice versa)

B. monolingual (English-English)

C. both

D. others (please state)

2. How often do you use the English monolingual dictionary?
A. everyday
B. about 3 to 5 times per week
C. about once a week
D. rarely
E. never

3. If you feel that you don't have the habit of looking up words in an English monolingual dictionary, why is it so?

A. I find it hard to understand the definition in the dictionary

B. It takes too long to find meaning of words

C. I don't think finding meanings of words are important

D. Other information about the words which I look up are too technical to understand

E. Others (please state)

4. Roughly, how would you grade your current skill in using the English monolingual dictionary? (The word skill means your understanding of all or most of the information about a word contained in the dictionary. These include, for example, your ability to understand the word meaning, the word part of speech or class, your ability to understand the example sentences, your ability to understand and use the different dictionary symbols for a word, etc.).
A. very high
B. high
C. average
D. low
E. very low

5. Have you had any classes given by your teachers/lecturers in which English monolingual dictionary skills were taught at any time when you were at school and/or at college/university?

A. yes

B. no

6. I think the English monolingual dictionary is important to me in learning English.
A. strongly agree
B. agree
C. not sure
D. disagree
E. strongly disagree

7. If there is a special class held for students at University Teknologi Malaysia, International Campus to teach English monolingual dictionary skills, would you like to attend it?
A. yes
B. not sure
C. no

8. If you have good knowledge about the English monolingual dictionary and good skill in using it, would you use the English monolingual dictionary more frequently?
A. yes
B. not sure
C. no 
9. Please write down specifically the reason/s why you refer to the English monolingual dictionary. I refer to them because I want to learn...

a.

b.

c.

d.

e.

f.

(You may add more reasons if you wish)

10. What kind of dictionary do you usually refer to?

A. desk dictionary (the big dictionary the size of half the A4 paper)

B. small pocket booklet dictionary

C. pocket electronic dictionary

D. online dictionary

E. others (please state)

Thank you for your cooperation 